\title{
Walking for Transportation or Leisure Among U.S. Women and Men - National Health Interview Survey, 2005-2015
}

\begin{abstract}
Emily N. Ussery, $\mathrm{PhD}^{1,2}$; Susan A. Carlson, $\mathrm{PhD}^{2}$; Geoffrey P. Whitfield ${ }^{2}$, PhD; Kathleen B. Watson, $\mathrm{PhD}^{2}$; David Berrigan, PhD ${ }^{3}$; Janet E. Fulton, PhD ${ }^{2}$
\end{abstract}
Physical activity confers considerable health benefits, but only half of U.S. adults report participating in levels of aerobic physical activity consistent with guidelines $(1,2)$. Step It $U p$ ! The Surgeon General's Call to Action to Promote Walking and Walkable Communities identified walking as an important public health strategy to increase physical activity levels (3). A previous report showed that the self-reported prevalence of walking for transportation or leisure increased by 6 percentage points from 2005 to 2010 (4), but it is unknown whether this increase has been sustained. CDC analyzed National Health Interview Survey (NHIS) data from 2005 (26,551 respondents), 2010 $(23,313)$, and $2015(28,877)$ to evaluate trends in the ageadjusted prevalence of self-reported walking among adults aged $\geq 18$ years. The prevalence of walking increased steadily among women, from $57.3 \%$ in 2005 , to $62.5 \%$ in 2010 , and to $65.1 \%$ in 2015 (significant linear trend). Among men, a significant linear increase in reported walking was observed, from $54.3 \%$ in 2005 , to $61.8 \%$ in 2010 , and to $62.8 \%$ in 2015, although the increase stalled between 2010 and 2015 (significant linear and quadratic trends). Community design policies and practices that encourage pedestrian activity and programs tailored to the needs of specific population subgroups remain important strategies for promoting walking (3).

NHIS is a continuous in-person survey of U.S. households designed to be representative of the civilian, noninstitutionalized population (5). NHIS consists of a core questionnaire that collects basic health and demographic information for all family members in a sampled household and supplements that collect information about specialized topics. Questions specific to walking for leisure and transportation were asked of one adult aged $\geq 18$ years per sampled household in the 2005, 2010, and 2015 Cancer Control Supplements. Sample adult response rates were 69.0\% (2005), 60.8\% (2010), and $55.2 \%(2015)(6)$.
Walking was defined as engaging in at least one 10-minute period of transportation or leisure walking in the past 7 days at the time of survey. To assess transportation walking, respondents in all 3 years were asked, "During the past 7 days, did you walk to get someplace that took you at least 10 minutes?" To assess leisure-time walking, respondents in 2005 were asked, "During the past 7 days, did you walk for at least 10 minutes at a time [for fun, relaxation, exercise, or to walk the dog]?" and in 2010 and 2015, "During the past 7 days, did you walk for at least 10 minutes [for fun, relaxation, exercise, or to walk the dog]?"

Demographic characteristics (sex, age, race/ethnicity, and education level) and health-related characteristics (height, weight, walking assistance status, and physical activity) were also assessed. Meeting the aerobic physical activity guideline of at least 150 minutes of moderate-intensity equivalent aerobic activity per week was assessed using responses on the usual

\section{INSIDE}

663 Multistate Outbreak of Salmonella Anatum Infections Linked to Imported Hot Peppers United States, May-July 2016

668 Update: Influenza Activity in the United States During the 2016-17 Season and Composition of the 2017-18 Influenza Vaccine

677 Notes from the Field: Late-Onset Infant Group B Streptococcus Infection Associated with Maternal Consumption of Capsules Containing Dehydrated Placenta - Oregon, 2016

679 QuickStats

Continuing Education examination available at https://www.cdc.gov/mmwr/cme/conted_info.html\#weekly.

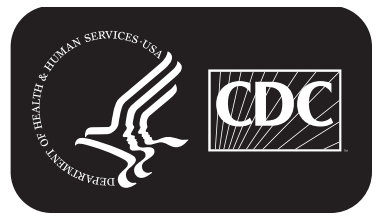

U.S. Department of Health and Human Services Centers for Disease Control and Prevention 
frequency and duration of light- to moderate-intensity and vigorous-intensity leisure-time physical activity (1).

From the initial total sample of 92,257 (31,428 [2005]; 27,157 [2010]; and 33,672 [2015]), 13,516 (15\%) persons were excluded, including 2,280 who were unable to walk and 11,236 for whom data were missing for walking $(6,044)$, physical activity $(1,054)$, health-related characteristics $(3,708)$, or demographic characteristics (430). Thus, the final analytic sample consisted of 78,741 respondents (26,551 [2005]; 23,313 [2010]; and 28,877 [2015]).

The proportion (with $95 \%$ confidence intervals) of adults who reported walking each year was calculated. Linear and quadratic trends in walking prevalence from 2005 to 2015 were tested using logistic regression, controlling for age group. For three time points, a temporal change that includes significant linear and quadratic trend terms indicates an overall increase or decrease over time as well as a deviation from linearity. For example, if the linear trend is positive and quadratic trend is negative, this indicates an increase from 2005 to 2015 with a stalling or leveling off between 2010 and 2015. Because significant interactions between sex and trend terms were observed, sex-specific results are presented. Subgroup analyses were conducted by age group, race/ethnicity, education level, U.S. Census region, body mass index category, walking assistance status, and meeting the aerobic physical activity guideline, and pairwise differences between subgroups and across years were tested using adjusted Wald tests. Statistically significant $(\mathrm{p}<0.05)$ results are reported. All analyses accounted for the complex survey design. Reported estimates are weighted and age-standardized to the 2000 U.S. standard population (7).

In 2015, women were significantly more likely to report walking $(65.1 \%)$ than were men $(62.8 \%)$ (Figure). Among women in 2015, the lowest reported prevalence of walking was among those aged $\geq 65$ years, non-Hispanic blacks (blacks), and residents of the South, compared with their respective counterparts (Table 1). Among men in 2015, the lowest prevalence of walking was among blacks and Hispanics and the highest prevalence was among men in the West, compared with their respective counterparts (Table 2). Among males, there were no significant age group differences in walking prevalence. The prevalence of walking was lower among men and women with a high school education or less, who had obesity, who needed walking assistance, or who did not meet aerobic physical activity guidelines than among their respective counterparts.

Among women, the prevalence of walking demonstrated a significant linear increase from 2005 to 2015, with no significant quadratic trend (Figure) (Table 1). This trend remained when stratified by selected characteristics, with two exceptions: both linear and quadratic trends were significant among women who were overweight or lived in the Midwest. The increase in walking prevalence among women between 2010 and 2015 was significant overall (2.7 percentage points) and among select strata (age 45-64 years, age $\geq 65$ years, non-Hispanic whites, college graduates, residents of the Northeast and South regions, those who were underweight or normal weight, those with obesity, and those not needing walking assistance).

The MMWR series of publications is published by the Center for Surveillance, Epidemiology, and Laboratory Services, Centers for Disease Control and Prevention (CDC), U.S. Department of Health and Human Services, Atlanta, GA 30329-4027.

Suggested citation: [Author names; first three, then et al., if more than six.] [Report title]. MMWR Morb Mortal Wkly Rep 2017;66:[inclusive page numbers].

\section{Centers for Disease Control and Prevention Anne Schuchat, MD, Acting Director \\ William R. Mac Kenzie, MD, Acting Associate Director for Science Joanne Cono, MD, ScM, Director, Office of Science Quality \\ Chesley L. Richards, MD, MPH, Deputy Director for Public Health Scientific Services \\ Michael F. Iademarco, MD, MPH, Director, Center for Surveillance, Epidemiology, and Laboratory Services}

MMWR Editorial and Production Staff (Weekly)

Sonja A. Rasmussen, MD, MS, Editor-in-Chief

Charlotte K. Kent, PhD, MPH, Executive Editor Jacqueline Gindler, MD, Editor

Teresa F. Rutledge, Managing Editor

Douglas W. Weatherwax, Lead Technical Writer-Editor

Soumya Dunworth, PhD, Kristy Gerdes, MPH, Teresa M. Hood, MS, Technical Writer-Editors

Timothy F. Jones, MD, Chairman

Matthew L. Boulton, MD, MPH Virginia A. Caine, MD

Katherine Lyon Daniel, $\mathrm{PhD}$

Jonathan E. Fielding, MD, MPH, MBA

David W. Fleming, MD

\section{MMWR Editorial Board}

William E. Halperin, MD, DrPH, MPH

King K. Holmes, MD, PhD

Robin Ikeda, MD, MPH

Rima F. Khabbaz, MD

Phyllis Meadows, PhD, MSN, RN

Jewel Mullen, MD, MPH, MPA
Martha F. Boyd, Lead Visual Information Specialist Maureen A. Leahy, Julia C. Martinroe, Stephen R. Spriggs, Tong Yang, Visual Information Specialists

Quang M. Doan, MBA, Phyllis H. King,

Terraye M. Starr, Moua Yang,

Information Technology Specialists
Jeff Niederdeppe, $\mathrm{PhD}$

Patricia Quinlisk, MD, MPH

Patrick L. Remington, MD, MPH Carlos Roig, MS, MA

William L. Roper, MD, MPH

William Schaffner, MD 
FIGURE. Percentage* of U.S. women ${ }^{\dagger}$ and men $^{\S}$ aged $\geq 18$ years who reported recent walking for transportation or leisure - National Health Interview Survey, 2005-2015

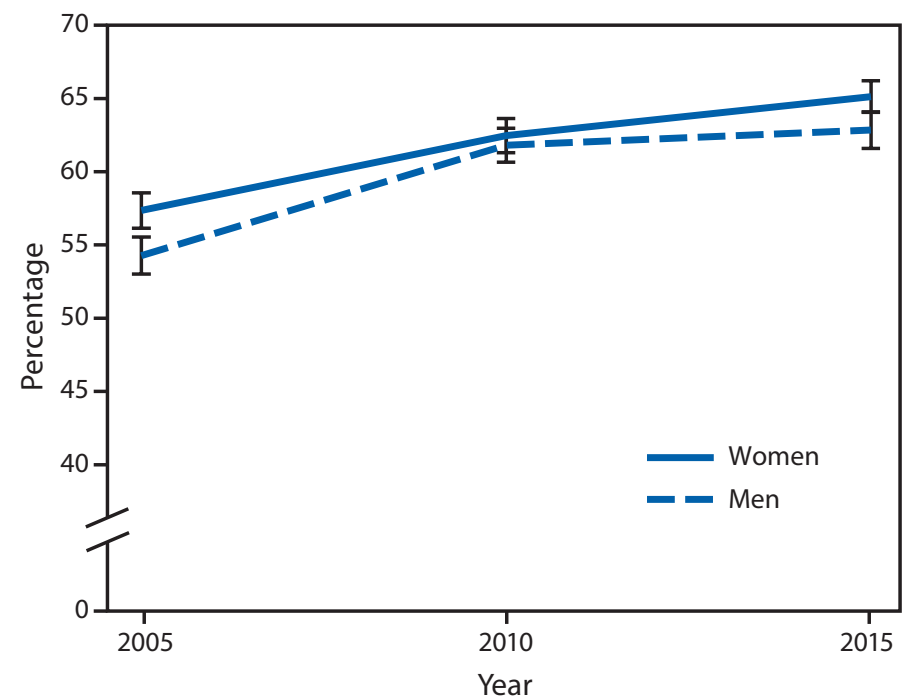

* Weighted percentages, age-standardized to the 2000 U.S. standard population. Error bars represent upper and lower bounds of $95 \%$ confidence intervals.

† Significant linear trend from 2005 to 2015 only $(p<0.05)$, based on trend analyses using logistic regression controlling for age category.

$\S$ Significant linear trend from 2005 to $2015(p<0.05)$ and a significant deviation from linear trend $(p<0.05)$, based on trend analyses using logistic regression controlling for age category.

Among men, a significant positive linear and negative quadratic trend in reported walking from 2005 to 2015 was observed overall and for most subgroups, with the increase stalling from 2010 to 2015 (Figure) (Table 2). The change in walking prevalence among men from 2010 to 2015 was not significant overall or when estimates were stratified by selected characteristics, with one exception: among men aged $\geq 65$ years, the prevalence of walking increased by 3.8 percentage points from 2010 to 2015.

\section{Discussion}

The prevalence of reported walking for transportation or leisure among men and women increased between 2005 and 2015; however, for men, the increase stalled between 2010 and 2015. This trend among males is similar to trends for leisure time physical activity, with the reported prevalence of meeting physical activity guidelines increasing steadily from 2008 to 2012 and stalling between 2012 and 2015 (2).* However, even given this increase, nearly one third of women and men report that they did not walk for at least 10 minutes in the past week.

Walking is an easy way for most adults to incorporate more physical activity into their daily routines. Women are less

\footnotetext{
${ }^{*}$ https://www.cdc.gov/physicalactivity/downloads/trends-in-the-prevalence-ofphysical-activity.pdf.
}

\section{Summary}

What is already known about this topic?

Only half of U.S. adults report achieving physical activity levels consistent with published guidelines. Walking is an easy way for most persons to be more physically active. Self-reported walking among adults increased by 6 percentage points from 2005 to 2010 , but it is unknown whether this increase has continued.

What is added by this report?

The prevalence of self-reported walking among women significantly increased from 2005 to 2015 (2005: 57.4\%; 2010: 62.5\%; 2015: 65.1\%); among men, the prevalence increased overall but stalled between 2010 and 2015 (2005: 54.3\%; 2010: $61.8 \% ; 2015: 62.8 \%)$. Sociodemographic disparities in walking prevalence exist, with the lowest prevalences among non-Hispanic blacks and persons with a high school education or less. Moreover, differences by education level appear to have widened over time among men, with walking prevalence increasing steadily among college graduates but leveling off among men with lower education levels.

What are the implications for public health practice?

To promote walking, streets and communities can be designed so that walking is a safe and convenient option for all persons. Communities can also implement walking programs that are tailored to the interests and abilities of specific population subgroups. Focused approaches to overcome barriers to walking in low socioeconomic status and minority communities, such as policies and practices that improve the safety and quality of community supports for physical activity (e.g. trails and sidewalks), might help reduce the observed disparities in walking.

likely than men to achieve physical activity levels sufficient to meet guidelines (2). However, this study found that walking has become increasingly common among women since 2005, representing a potential opportunity for addressing the gender difference in overall physical activity. Efforts to sustain the observed increase in the percentage of adults who walk could contribute to more adults meeting guidelines, potentially reducing the burden of chronic diseases and premature death associated with low levels of physical activity. For example, communities can create additional opportunities for walking by implementing walking programs tailored to the interests and abilities of specific subgroups of the population (3). In addition, policies and practices that improve the safety of communities and promote walkable design can help make walking a convenient option for almost all persons.

For both women and men, walking was least prevalent among blacks and persons with lower educational attainment, groups that have been shown to report lower levels of physical activity compared to their counterparts (8). In some cases, differences in walking appear to be widening over time. For example, among men, walking increased at a steady rate among college graduates from 2005 to 2015 (significant linear 
Morbidity and Mortality Weekly Report

TABLE 1. Proportion of U.S. women aged $\geq 18$ years who reported recent walking for transportation or leisure, by selected demographic and health characteristics - National Health Interview Survey, 2005-2015

\begin{tabular}{|c|c|c|c|c|}
\hline \multirow[b]{2}{*}{ Characteristic } & \multicolumn{3}{|c|}{$\% *(95 \% \mathrm{Cl})$} & \multirow[b]{2}{*}{$\begin{array}{l}\text { Absolute change from } \\
2010 \text { to } 2015\end{array}$} \\
\hline & $\begin{array}{c}2005 \\
(n=14,609)\end{array}$ & $\begin{array}{c}2010 \\
(n=12,734)\end{array}$ & $\begin{array}{c}2015 \\
(n=15,562)\end{array}$ & \\
\hline Total & $57.4(56.1-58.6)$ & $62.5(61.3-63.6)$ & $65.1(64.0-66.2)^{\dagger}$ & $2.7^{\S}$ \\
\hline \multicolumn{5}{|l|}{ Age group (yrs) } \\
\hline $18-24$ & $61.4(58.0-64.7)$ & $65.4(62.1-68.6)$ & $66.2(62.5-69.8)$ & 0.8 \\
\hline $25-34$ & $59.7(57.3-62.1)$ & $66.6(64.1-69.0)$ & $69.0(66.7-71.2)^{\dagger}$ & 2.4 \\
\hline $35-44$ & $62.1(59.9-64.3)$ & $66.2(63.8-68.5)$ & $68.4(65.9-71.0)^{\dagger}$ & 2.2 \\
\hline $45-64$ & $56.7(54.9-58.6)$ & $62.8(61.0-64.6)$ & $65.7(63.8-67.5)^{\dagger}$ & $2.9^{\S}$ \\
\hline$\geq 65$ & $46.8(44.6-49.0)$ & $50.6(48.1-53.0)$ & $55.0(52.8-57.2)^{\dagger}$ & $4.4^{\S}$ \\
\hline \multicolumn{5}{|l|}{ Race/Ethnicity } \\
\hline White, non-Hispanic & $59.5(58.0-60.9)$ & $64.0(62.6-65.5)$ & $66.6(65.2-68.1)^{\dagger}$ & $2.6^{\S}$ \\
\hline Black, non-Hispanic & $47.5(45.0-50.1)$ & $53.8(51.2-56.5)$ & $55.5(52.4-58.5)^{\dagger}$ & 1.7 \\
\hline Hispanic & $54.0(51.0-57.0)$ & $60.6(58.2-63.0)$ & $63.9(61.5-66.3)^{\dagger}$ & 3.3 \\
\hline Other race & $59.2(55.2-63.3)$ & $66.9(63.8-69.9)$ & $69.9(66.6-73.3)^{\dagger}$ & 3.0 \\
\hline \multicolumn{5}{|l|}{ Education level } \\
\hline Less than high school graduate & $47.0(44.3-49.7)$ & $51.2(48.4-54.0)$ & $55.1(52.2-58.0)^{\dagger}$ & 3.9 \\
\hline High school graduate & $49.8(47.8-51.9)$ & $55.6(53.4-57.9)$ & $56.4(54.1-58.7)^{\dagger}$ & 0.8 \\
\hline Some college & $59.9(57.9-61.8)$ & $63.4(61.3-65.4)$ & $63.7(61.9-65.6)^{\dagger}$ & 0.3 \\
\hline College graduate & $68.5(66.3-70.7)$ & $72.4(70.3-74.4)$ & $76.0(74.2-77.8)^{\dagger}$ & $3.6^{\S}$ \\
\hline \multicolumn{5}{|l|}{ U.S. Census region } \\
\hline Northeast & $66.1(63.8-68.5)$ & $65.7(62.8-68.5)$ & $70.4(68.0-72.8)^{\dagger}$ & $4.7^{\S}$ \\
\hline Midwest & $56.7(54.3-59.0)$ & $62.6(60.4-64.9)$ & $62.9(60.8-65.1)^{\dagger, * *}$ & 0.3 \\
\hline South & $50.8(48.6-52.9)$ & $56.4(54.3-58.4)$ & $59.9(57.9-61.9)^{\dagger}$ & $3.6^{\S}$ \\
\hline West & $61.8(59.4-64.2)$ & $69.2(66.9-71.5)$ & $71.8(69.8-73.8)^{\dagger}$ & 2.6 \\
\hline \multicolumn{5}{|l|}{ Body mass index category ${ }^{\dagger+}$} \\
\hline Underweight/Normal weight & $61.4(59.9-62.9)$ & $66.6(65.0-68.2)$ & $70.3(68.8-71.8)^{\dagger}$ & $3.7^{\S}$ \\
\hline Overweight & $56.7(54.6-58.7)$ & $63.8(62.0-65.6)$ & $65.0(63.1-66.9)^{\dagger, * *}$ & 1.2 \\
\hline Has obesity & $50.0(47.9-52.0)$ & $54.6(52.5-56.8)$ & $57.8(55.9-59.7)^{\dagger}$ & $3.1^{\S}$ \\
\hline \multicolumn{5}{|l|}{ Walking assistance status $§ \S$} \\
\hline Does not need assistance & $59.7(58.5-61.0)$ & $65.3(62.6-64.9)$ & $67.9(63.1-65.6)^{\dagger}$ & $2.6^{\S}$ \\
\hline Needs assistance & $25.8(20.5-31.0)$ & $23.6(19.3-34.2)$ & $30.3(23.1-35.6)$ & 6.7 \\
\hline \multicolumn{5}{|c|}{ Meets aerobic physical activity guideline $\mathrm{e}^{\text {Iึ }}$} \\
\hline No & $44.6(43.2-46.1)$ & $49.1(47.6-50.7)$ & $51.0(49.5-52.6)^{\dagger}$ & 1.9 \\
\hline Yes & $76.8(75.4-78.1)$ & $79.3(78.0-80.7)$ & $80.6(79.3-82.0)^{\dagger}$ & 1.3 \\
\hline
\end{tabular}

Abbreviation: $\mathrm{Cl}$ = confidence interval.

* Weighted percentages, age-standardized to the 2000 U.S. standard population.

† Significant linear trend from 2005 to 2015 ( $p<0.05)$, based on trend analyses using logistic regression controlling for age category.

$\S$ Significant change from 2010 to 2015 ( $p<0.05)$.

9 "Other race" category includes non-Hispanic Asian, non-Hispanic American Indian/Alaskan Native, and persons reporting more than one race.

** Significant deviation from linear trend from 2005 to 2015 ( $p<0.05)$, based on trend analyses using logistic regression controlling for age category.

${ }^{+\dagger}$ Body mass index (weight $[\mathrm{kg}] /$ height $\left[\mathrm{m}^{2}\right]$ ) estimates were calculated from self-reported weight and height. Underweight and normal weight: $<25.0$, overweight: 25.0-29.9, and has obesity: $\geq 30$.

$\S \S$ Needing walking assistance was defined as being unable or finding it very difficult "to walk one-quarter mile without special equipment."

ๆๆ Meeting the 2008 aerobic physical activity guideline was defined as participating in $\geq 150$ minutes of moderate-intensity equivalent aerobic activity per week (light- to moderate-intensity minutes plus two times vigorous-intensity minutes).

trend only), but stalled between 2010 and 2015 among those who did not graduate from high school (significant linear and quadratic trends). Low socioeconomic status (SES) and minority neighborhoods are often perceived as less attractive and less safe because of traffic or crime when compared with higher SES and majority white neighborhoods (9). Efforts to overcome such environmental barriers to walking in these communities, like policies and practices that improve the safety and quality of community supports for physical activity (e.g., trails and sidewalks), might help to reduce the observed disparities in walking (3).

The findings in this report are subject to at least four limitations. First, this analysis relies on self-reported data, and social desirability bias might result in overestimates of walking (10). Second, the wording of the question about leisure walking changed slightly between 2005 and 2010; to improve comparability between years, participants in all years who reported that a typical walking period lasted $<10$ minutes 
TABLE 2. Proportion of U.S. men aged $\geq 18$ years who reported recent walking for transportation or leisure, by selected demographic and health characteristics — National Health Interview Survey, 2005-2015

\begin{tabular}{|c|c|c|c|c|}
\hline \multirow[b]{2}{*}{ Characteristic } & \multicolumn{3}{|c|}{$\% *(95 \% \mathrm{Cl})$} & \multirow[b]{2}{*}{$\begin{array}{l}\text { Absolute change } \\
\text { from } 2010 \text { to } 2015\end{array}$} \\
\hline & $\begin{array}{c}2005 \\
(n=11,942)\end{array}$ & $\begin{array}{c}2010 \\
(n=10,579)\end{array}$ & $\begin{array}{c}2015 \\
(n=13,315)\end{array}$ & \\
\hline Total & $54.3(53.0-55.5)$ & $61.8(60.6-63.0)$ & $62.8(61.6-64.1)^{\dagger, \S}$ & 1.0 \\
\hline $\begin{array}{l}\text { Age group (yrs) } \\
18-24 \\
25-34 \\
35-44 \\
45-64 \\
\geq 65\end{array}$ & $\begin{array}{l}56.0(52.5-59.4) \\
52.5(50.0-55.0) \\
54.4(52.1-56.7) \\
54.5(52.7-56.4) \\
54.3(51.6-56.9)\end{array}$ & $\begin{array}{l}65.7(62.2-69.3) \\
63.7(61.0-66.3) \\
61.3(58.7-63.9) \\
61.8(60.0-63.7) \\
57.4(54.6-60.2)\end{array}$ & $\begin{array}{l}63.6(59.8-67.5)^{\dagger, \S} \\
64.5(61.9-67.2)^{\dagger, \S} \\
62.3(59.2-65.3)^{\dagger} \\
62.8(60.8-64.8)^{\dagger, \S} \\
61.2(58.9-63.5)^{\dagger}\end{array}$ & $\begin{array}{r}-2.1 \\
0.8 \\
1.0 \\
1.0 \\
3.8\end{array}$ \\
\hline $\begin{array}{l}\text { Race/Ethnicity } \\
\text { White, non-Hispanic } \\
\text { Black, non-Hispanic } \\
\text { Hispanic } \\
\text { Other race } \\
\text { *t* }\end{array}$ & $\begin{array}{l}55.1(53.6-56.6) \\
50.8(47.9-53.7) \\
52.5(49.6-55.3) \\
53.8(48.5-59.1)\end{array}$ & $\begin{array}{l}62.9(61.5-64.3) \\
55.5(52.3-58.7) \\
60.1(57.4-62.8) \\
64.5(60.6-68.4)\end{array}$ & $\begin{array}{l}64.1(62.4-65.8)^{\dagger, \S} \\
58.3(55.2-61.4)^{\dagger} \\
59.6(56.7-62.5)^{\dagger, \S} \\
67.6(64.2-71.1)^{\dagger}\end{array}$ & $\begin{array}{r}1.2 \\
2.8 \\
-0.5 \\
3.1\end{array}$ \\
\hline $\begin{array}{l}\text { Education level } \\
\text { Less than high school graduate } \\
\text { High school graduate } \\
\text { Some college } \\
\text { College graduate }\end{array}$ & $\begin{array}{l}46.1(43.6-48.7) \\
46.5(44.4-48.5) \\
55.7(53.7-57.8) \\
64.8(62.4-67.2)\end{array}$ & $\begin{array}{l}53.8(51.1-56.5) \\
55.5(53.3-57.6) \\
61.6(59.5-63.7) \\
71.5(69.3-73.7)\end{array}$ & $\begin{array}{l}53.3(50.0-56.6)^{\dagger, \S} \\
56.2(53.7-58.6)^{\dagger, \S} \\
61.0(58.8-63.2)^{\dagger, \S} \\
72.8(70.8-74.9)^{\dagger}\end{array}$ & $\begin{array}{r}-0.5 \\
0.7 \\
-0.6 \\
1.3\end{array}$ \\
\hline $\begin{array}{l}\text { U.S. Census region } \\
\text { Northeast } \\
\text { Midwest } \\
\text { South } \\
\text { West }\end{array}$ & $\begin{array}{l}61.8(58.9-64.6) \\
54.2(51.7-56.6) \\
47.8(45.7-50.0) \\
58.8(56.0-61.6)\end{array}$ & $\begin{array}{l}66.2(63.5-69.0) \\
60.4(58.0-62.7) \\
57.5(55.4-59.6) \\
66.3(64.0-68.7)\end{array}$ & $\begin{array}{l}63.7(60.8-66.6)^{\S} \\
61.0(58.5-63.5)^{\dagger, \S} \\
59.6(57.5-61.7)^{\dagger, \S} \\
68.7(66.0-71.5)^{\dagger}\end{array}$ & $\begin{array}{r}-2.6 \\
0.6 \\
2.2 \\
2.4\end{array}$ \\
\hline $\begin{array}{l}\text { Body mass index category }{ }^{\dagger \dagger} \\
\text { Underweight/Normal weight } \\
\text { Overweight } \\
\text { Has obesity }\end{array}$ & $\begin{array}{l}54.8(52.7-56.9) \\
55.8(54.0-57.6) \\
51.8(49.5-54.1)\end{array}$ & $\begin{array}{l}63.9(62.0-65.9) \\
62.8(61.0-64.6) \\
58.2(56.1-60.4)\end{array}$ & $\begin{array}{l}64.3(62.0-66.5)^{\dagger, \S} \\
63.0(61.3-64.8)^{\dagger, \S} \\
60.8(58.4-63.2)^{\dagger}\end{array}$ & $\begin{array}{l}0.4 \\
0.2 \\
2.6\end{array}$ \\
\hline $\begin{array}{l}\text { Walking assistance status }{ }^{\S} \\
\text { Does not need assistance } \\
\text { Needs assistance }\end{array}$ & $\begin{array}{l}55.8(54.5-57.1) \\
26.6(19.5-33.8)\end{array}$ & $\begin{array}{l}63.8(62.6-64.9) \\
26.7(19.3-34.2)\end{array}$ & $\begin{array}{l}64.4(63.1-65.6)^{\dagger, \S} \\
29.3(23.1-35.6)^{\dagger}\end{array}$ & $\begin{array}{l}0.6 \\
2.6\end{array}$ \\
\hline $\begin{array}{l}\text { Meets aerobic physical activity } \\
\text { No } \\
\text { Yes }\end{array}$ & $\begin{array}{l}41.0(39.3-42.6) \\
70.5(69.0-71.9)\end{array}$ & $\begin{array}{l}48.4(46.7-50.1) \\
74.5(73.1-76.0)\end{array}$ & $\begin{array}{l}47.5(45.5-49.4)^{\dagger, \S} \\
76.2(74.8-77.5)^{\dagger}\end{array}$ & $\begin{array}{r}-0.9 \\
1.7\end{array}$ \\
\hline
\end{tabular}

Abbreviation: $\mathrm{Cl}=$ confidence interval.

* Weighted percentages, age-standardized to the 2000 U.S. standard population.

† Significant linear trend from 2005 to $2015(\mathrm{p}<0.05)$, based on trend analyses using logistic regression controlling for age category.

§ Significant deviation from linear trend from 2005 to $2015(p<0.05)$, based on trend analyses using logistic regression controlling for age category.

" Significant change from 2010 to 2015 ( $p<0.05)$.

** "Other race" category includes non-Hispanic Asian, non-Hispanic American Indian/Alaskan Native, and persons reporting more than one race.

${ }^{+\dagger}$ Body mass index (weight $[\mathrm{kg}] /$ height $\left[\mathrm{m}^{2}\right]$ ) estimates were calculated from self-reported weight and height. Underweight and normal weight: $<25.0$, overweight: 25.0-29.9, and has obesity: $\geq 30$.

$\S \S$ Needing walking assistance was defined as being unable or finding it very difficult "to walk one-quarter mile without special equipment."

१ศ Meeting the 2008 aerobic physical activity guideline was defined as participating in $\geq 150$ minutes of moderate-intensity equivalent aerobic activity per week (light- to moderate-intensity minutes plus two times vigorous-intensity minutes).

(1,076 respondents) were categorized as nonwalkers. Third, survey response rates could contribute to response bias if nonresponders differed systematically from responders, although weighting procedures should reduce the impact of survey nonresponse. Finally, approximately $6 \%$ of respondents were missing walking data each year; the application of sample weights would not be expected to mitigate any potential bias associated with missing data.
The reported prevalence of transportation or leisure walking among women and men increased from 2005 to 2015, although among men, the increase has stalled in recent years. By implementing community and street scale design strategies that encourage pedestrian activity and by supporting walking programs where persons spend their time, communities can improve walkability and make walking a safer and easier option for increasing physical activity (3).

\section{Conflict of Interest}

No conflicts of interest were reported. 
${ }^{1}$ Epidemic Intelligence Service, CDC; ${ }^{2}$ Division of Nutrition, Physical Activity, and Obesity, National Center for Chronic Disease Prevention and Health Promotion, CDC; ${ }^{3}$ Division of Cancer Control \& Population Sciences, National Cancer Institute, Bethesda, Maryland.

Corresponding author: Emily N. Ussery, yzv4@cdc.gov, 770-488-3766.

\section{References}

1. US Department of Health and Human Services. 2008 physical activity guidelines for Americans. Washington, DC: US Department of Health and Human Services; 2008. https://health.gov/paguidelines/guidelines/

2. US Department of Health and Human Services. HP2020 objective data search website. Physical activity. Washington, DC: US Department of Health and Human Services; 2017. https://www.healthypeople. gov/2020/data-search/Search-the-Data?nid=5069

3. US Department of Health and Human Services. Step it up! The Surgeon General's call to action to promote walking and walkable communities. Washington, DC: US Department of Health and Human Services, Office of the Surgeon General. 2015. https://www.surgeongeneral.gov/ library/calls/walking-and-walkable-communities/index.html

4. CDC. Vital signs: walking among adults-United States, 2005 and 2010. MMWR Morb Mortal Wkly Rep 2012;61:595-601.
5. National Center for Health Statistics. National Health Interview Survey. Atlanta, GA: US Department of Health and Human Services, CDC, National Center for Health Statistics; 2017. https://www.cdc.gov/nchs/nhis.htm

6. National Center for Health Statistics. National Health Interview Survey. Survey description. June 2016. Hyattsville, MD: US Department of Health and Human Services, CDC, National Center for Health Statistics, Division of Health Interview Statistics; 2016. ftp://ftp.cdc.gov/pub/Health_ Statistics/NCHS/Dataset_Documentation/NHIS/2015/srvydesc.pdf

7. Klein RJ, Schoenborn CA. Age adjustment using the 2000 projected U.S. population. Healthy People 2010 Stat Notes 2001;20:1-9.

8. Bauman AE, Reis RS, Sallis JF, Wells JC, Loos RJ, Martin BW; Lancet Physical Activity Series Working Group. Correlates of physical activity: why are some people physically active and others not? Lancet 2012;380:258-71. https://doi.org/10.1016/S0140-6736(12)60735-1

9. Lovasi GS, Hutson MA, Guerra M, Neckerman KM. Built environments and obesity in disadvantaged populations. Epidemiol Rev 2009;31:7-20. https://doi.org/10.1093/epirev/mxp005

10. Adams SA, Matthews CE, Ebbeling CB, et al. The effect of social desirability and social approval on self-reports of physical activity. Am J Epidemiol 2005;161:389-98. https://doi.org/10.1093/aje/kwi054 